\title{
Pregnancy and marriage among teenage schoolgirls in rural western Kenya; a secondary analysis of a menstrual solution feasibility cohort study
}

\author{
Elizabeth Nyothach ${ }^{1}$, Eleanor Ambrose², Anna M. Van Eijk ${ }^{3}$, David Obor ${ }^{1}$, Linda Mason ${ }^{3}$, \\ Clifford Oduor $^{1}$, Garazi Zulaika ${ }^{3}$, Kayla F. Laserson ${ }^{3}$, Penelope A. Phillips Howard ${ }^{3 *}$
}

${ }^{1}$ Centre for Global Health Research, Kenya Medical Research Institute, Kisumu, Kenya

${ }^{2}$ Health and Life Sciences, Liverpool University, Liverpool, United Kingdom

${ }^{3}$ Department of Clinical Sciences, Liverpool School of Tropical Medicine, Liverpool, United Kingdom

Received: 29 April 2021

Revised: 29 July 2021

Accepted: 30 July 2021

\section{*Correspondence:}

Penelope A. Phillips Howard,

E-mail: Penelope.Phillips-Howard@1stmed.ac.uk

Copyright: () the author(s), publisher and licensee Medip Academy. This is an open-access article distributed under the terms of the Creative Commons Attribution Non-Commercial License, which permits unrestricted non-commercial use, distribution, and reproduction in any medium, provided the original work is properly cited.

\section{ABSTRACT}

Background: Adolescent pregnancy increases the risk of adverse health outcomes, social stigma, loss of education and employment, and early marriage. Research characterising at risk girls will inform targeting of effective interventions. Methods: Risk characteristics for adolescent pregnancy were evaluated in schoolgirls aged 14-16 years as a secondary analysis in a longitudinal study evaluating menstrual products in 30 primary schools in rural western Kenya. Characteristics of participants were collected at baseline and follow-up. Descriptive and multivariate analysis were conducted.

Results: Of 766 girls enrolled into the study, aged 14-16 years and followed over a school year, 53 (7\%) were or became pregnant, with three $(6 \%)$ neonatal deaths reported. Girls with the lowest compared with the highest socio-economic status had 2.5-fold higher risk of pregnancy (13.1\% vs 5.0\%: adjusted risk ratio (aRR) 2.48, confidence limits 1.32 4.64). Girls reporting early menarche ( $<13$ years) had a 2.5 -fold higher risk of pregnancy (aRR $2.61,1.38-4.92)$, while those happy in school had a reduced risk (aRR 0.60, 0.34-1.04). Age, presence of parents, and being harassed by boys or men were not associated with pregnancy risk. Twenty-two girls $(2.9 \%)$ married by the study end. Marriage was significantly associated with pregnancy (aRR 13.44, 5.50-32.83) and a history of sex at baseline $(3.15,1.55-6.38)$. All but two girls dropped out of school when pregnant with only five girls returning after delivery.

Conclusions: Pregnancy leading to school dropout and child marriage remains an urgent public health concern among teenage girls in rural Kenya. Interventions are needed to enable schoolgirls to reach their educational potential.

Keywords: Pregnancy, Schoolgirls, Adolescence, Sexual and reproductive health, Child marriage, Education

\section{INTRODUCTION}

Adolescent pregnancy is a global problem driving and exacerbating poverty. It is estimated that approximately 10 million unintended pregnancies, and 12 million births occur among girls 15-19 years in low-middle income countries (LMIC) annually. ${ }^{1}$ In a review of adolescent pregnancies in sub-Saharan Africa between 2003 and
2018, the highest rate of pregnancies were documented in east Africa (21.5\%) and lowest in Northern Africa (9.2\%). ${ }^{2}$ Globally and nationally, adolescent pregnancies occur more frequently in marginalised groups, driven by poverty, lower levels of education and employment opportunities, and a lack of reproductive freedom. ${ }^{3}$ SubSaharan African (SSA) schoolgirl pregnancies make a significant contribution to the gender gap in educational 
attainment. ${ }^{4}$ The poorest regions of the world have a 4 -fold higher birth rate for 15-19y-olds compared to that in highincome regions. ${ }^{5}$ As well as a higher frequency of pregnancy among poorer populations, pregnancy further amplifies pre-existing poverty. Research in South Africa, for example found children of teenage mothers had lower levels of school achievement. ${ }^{6}$

Pregnancy-related dropout in east Africa is well documented in Tanzania, Uganda, and Kenya, with teachers reporting a third of dropouts were due to pregnancy. ${ }^{7-9}$ In Uganda, a survey in 20 districts noted $\sim 20 \%$ of girls compared to $2 \%$ of boys aged $15-19$ years were married or living with a partner. ${ }^{8}$ Throughout Kenya, $11.8 \%$ of girls and $8.4 \%$ of boys aged between $10-24$ years had received no education in $2014,{ }^{10}$ while $37 \%$ and $43 \%$ of young adult females and males 20-24 years, respectively had completed secondary school. ${ }^{10}$ World bank studies indicate that girls who complete secondary education can earn up to 5 times more than those without education, with a one-third reduction in their total fertility which would reduce population growth and generate a large demographic dividend. ${ }^{11}$ Adolescent pregnancy is associated with maternal and newborn complications and is the primary cause of death for girls in this age group in LMIC. ${ }^{1,12}$ Adolescent mothers <20 years face higher risks of eclampsia, puerperal endometritis and systemic infections than those aged 20-24 years, and babies of adolescent mothers are at greater risk of low birth weight, preterm delivery and severe neonatal conditions. ${ }^{13}$ Infants are also more likely to be of low birth weight impacting their health and development. ${ }^{1}$ Prevention of pregnancy in adolescent schoolgirls is thus vital to achieving several of the sustainable development goals, including quality education, gender equality, good health and well-being, feeding into cessation of poverty. ${ }^{14}$

In Kenya, a quarter of women aged 25-49 years reported they first gave birth by age 18 years and a half by age 20 years, with $\sim 18 \%$ of girls aged 15-19 years having experienced pregnancy. ${ }^{10,15}$ Kenya started policy development for adolescent sexual and reproductive health in 2003; however, dissemination of the policy has been limited and not applied equitably missing the most vulnerable and difficult to reach. ${ }^{16}$ In the 2014 demographic and health survey, the proportion of teenagers becoming pregnant had not changed, suggesting that interventions thus far have had little effect. ${ }^{10}$

Among 1,952 girls aged 13-19 years in a home-based cross-sectional survey in rural western Kenya, 23.3\% reported they had ever been pregnant, three-quarters of whom had not wanted to become pregnant, with lower rates of school completion occurring among those pregnant. ${ }^{17}$ We sought to evaluate if a similar rate of pregnancy is occurring while girls are still in school, which girls are at greatest risk, and whether they can continue their schooling, utilizing data from a primary school-based study evaluating menstrual solutions among girls aged 1416 years. $^{18}$

\section{METHODS}

\section{Study type}

Secondary analysis of a longitudinal cohort study was done.

\section{Study place}

The study was conducted in 30 schools in Gem SubCounty in Siaya County, western Kenya. This rural area, located a few miles north of Lake Victoria, has a population of $\sim 82,000$ of whom $\sim 10,000$ (12\%) comprise girls aged 10-19 years. ${ }^{19}$ The population is predominantly rural, existing on subsistence farming and local trading, and of Luo ethnicity. ${ }^{19}$ The area is served by a health and demographic surveillance system (HDSS) by the Kenya Medical Research Institute (KEMRI).

\section{Study period}

This study took place from August 2012 to November 2013.

\section{Selection criteria}

Selection criteria for the Menstrual Solutions study (MS study), which examined the acceptability, use and safety of menstrual items, among girls in 30 primary schools in western Kenya was as follows: (i) school selection was based on an agreement by the head teacher to participate, if minimum water, sanitation and hygiene (WASH) criteria were achieved, the school was not enrolled in another study, or had ineligible class years, discussed in detail elsewhere; and (ii) schoolgirls were selected and enrolled if they were 14-16 years (y) of age, had no precluding disability (assessed by the enrolling nurse as severely disabled), had experienced at least three menses, were resident for a minimum of 4 months in the study area, and provided written assent (schoolgirl) and consent (parents/caregivers). ${ }^{18,20}$

\section{Procedures}

For the main study, the 30 selected schools were randomized into the three study groups [(menstrual cups, sanitary pads, or usual practice (e.g. used the same materials as prior to the study)] through randomization ceremonies in the community with school head teachers and district education officials. ${ }^{18}$ Pre-intervention, girls received puberty and hygiene education and specific training on their allocated menstrual item. At baseline, participants were taught how to use netbooks $\left(2 \mathrm{go}^{\mathrm{TM}}\right.$ Convertible Classmate PC) to enable them to selfcomplete the survey privately through the netbook. Study nurses provided girls with the assigned menstrual items after baseline screening. Girls were followed on average twice per term. Rolling enrolment was used so that girls who did not meet these criteria at the start of the study were included if their circumstances changed to fit the criteria 
(Figure 1). Girls who aged beyond the enrolment criteria of 14-16 years were retained in the study. This resulted in length of study participation varying amongst participants, with a median duration of 10.9 months. At enrolment, baseline characteristics of each participant were gathered through an interview with a study nurse, and a selfcompleted behavioural survey.

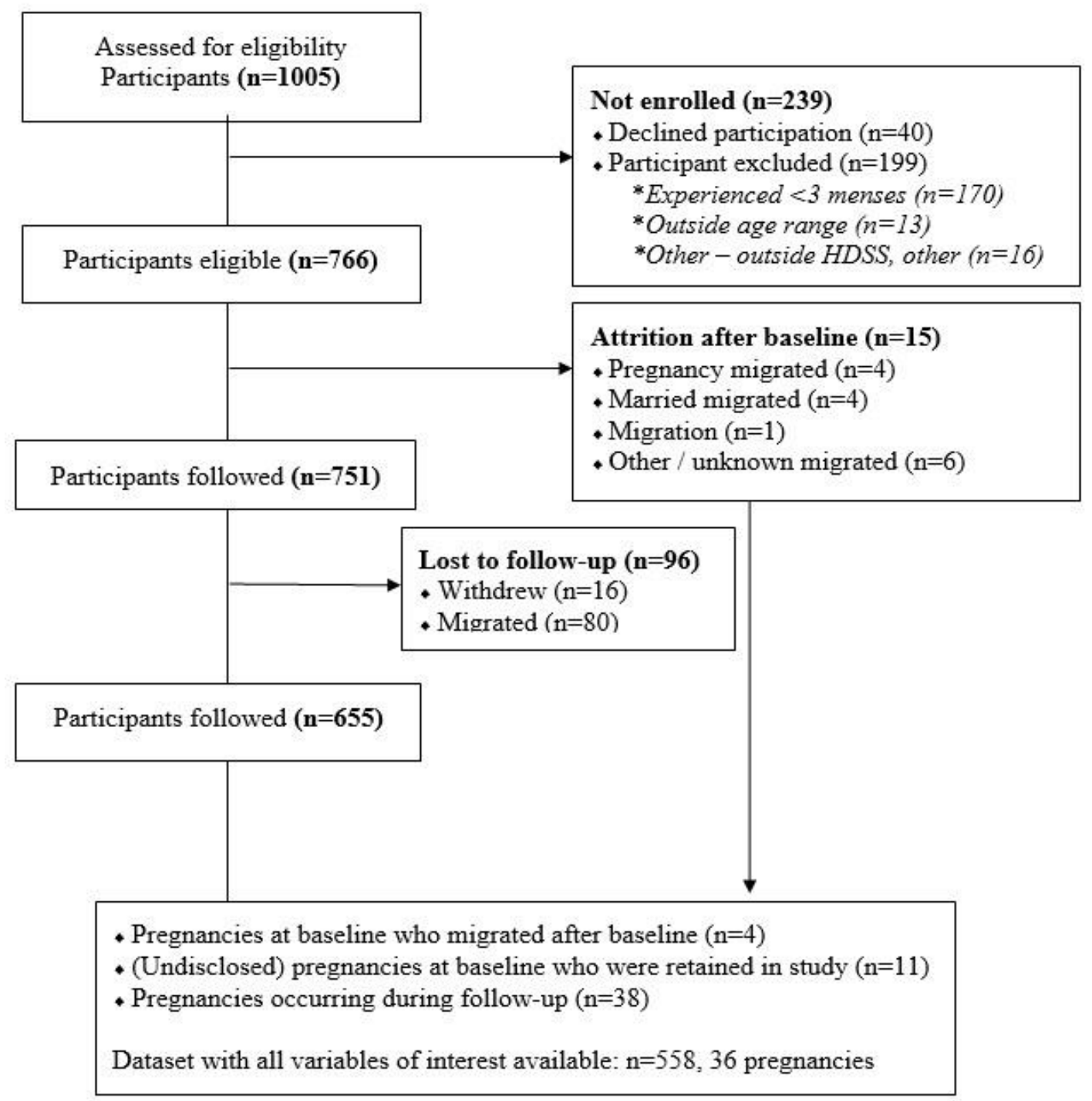

Figure 1: Participants flow diagram.

Nurse interview questions recorded girls' school class, their ages, start of menstruation, age at menarche, menstrual flow (light, normal, heavy), usual menstrual product used, and if there was a disability precluding inclusion. The behavioural survey included questions on who they live with in their household, their marital status, if they were happy at school, and if happy at home, if they were 'harassed for sex' in-school and/or out-of-school, if they had ever had sex or been tricked or coerced to have sex, if they had ever been pregnant. Socio-economic characteristics were obtained for 639 girls who could be linked with KEMRI's HDSS SES census survey on households. Pregnancy was identified through questioning girls on whether they were or had ever been pregnant, their date of their last menstrual period, and study nurses observing physical evidence in their school visits, followed by confidential questioning if she had missed her menses. Additionally, some girls also disclosed their pregnancy status to the study nurse. Girls who dropped out of school were detected as pregnant by our routine home follow-up to document reason for absence. The field worker would establish an estimated delivery date (e.g. from date of last menstrual period or conception) and record birth outcomes if possible, and guide girls on antenatal care services. Study nurses then re-visited all girls at the end of the study and recorded all birth outcomes.

\section{Ethical approval}

Ethical approval for the study was granted by the Ethics Committee of the Liverpool School of Tropical Medicine 
(12.11) and the Scientific and Ethical Review Boards of the Kenya Medical Research Institute (SSC No 2198). Written assent was provided by the schoolgirls, and written consent by the parents. Nurses were available throughout the study to support safeguarding and counselling to deal with any questions or concerns the girls had.

\section{Data analysis}

Descriptive statistics were generated to characterise the sample of girls at baseline. Socio-economic status (SES) quintiles for the girls' household at time of enrolment was generated using multiple component analysis, ${ }^{19}$ which was collapsed into the 'lowest' which included the lowest 2 quintiles, and 'highest' which composed the upper three quintiles. Other variables collapsed included age $(14,15-$ 16 years), school class $(5-6,7-8)$, early menarche was defined as a threshold of self-reported menarche $<13$ years, and ever had sex (combining willing sexual intercourse, and those tricked or coerced into having sex). Participants responses to 'happy' at home, and at school, were analysed as a dichotomous (yes/no) variable. Marriage was classified as reported marriage or cohabiting with their partner. Child marriage is defined as marriage $<18$ years. Characteristics associated with pregnancyrelated outcomes were evaluated in bi-variate analyses using chi squared tests with significance level set at 5\%, and risk ratios, with $95 \%$ confidence intervals (CI). Multivariate analysis was conducted using generalized linear regression models with a log link and binomial distribution, controlling for school cluster, among 558 girls with complete data on all variables, to explore associations with pregnancy, and with marriage. ${ }^{21}$ Variables included in the multivariate model of pregnancy or marriage if they had a p-value of $<0.1$ in univariate analysis; age was included in all models because age was an important risk factor in the literature. ${ }^{22}$ The variable 'ever had sex' was included in the analysis for marriage but not for pregnancy. Absence of SES was examined to determine if this missing data caused bias against outcomes (pregnancy, marriage, dropout) and risk characteristics through bivariate and multivariate analyses. Data were analysed using SPSS for Windows (Release v25.0; IBM, Endicott, NY, USA) and Stata (Stata/IC version 14.2, StataCorp LP, College Station, USA).

\section{RESULTS}

\section{Baseline characteristics}

Of the 766 primary schoolgirls enrolled for study, over half $(53.8 \%)$ were aged 14 years (Table 1$)$, with a median age of 14 years. Three-quarters of girls had at least one parent present in their household. Among 639 (83\%) girls whose home data could be linked, $18.5 \%$ were in the lowest SES two quintiles, with $31.5 \%$ in the highest SES quintile. Three quarters of girls reported being happy at home, and over four in five reported being happy at school. Most $(80.3 \%)$ girls reported menarche started between the age of 13-14 years (Table 1), with a mean and median age of menarche of 13.6 years (sd 0.9) and 14 years (IQR 13-15 years), respectively. One in ten girls reported early menarche (<13 years) (Table 1$)$. Just under one quarter considered their periods were heavy, and over four in five reported they had ever used branded sanitary pads. Being harassed for sex by boys and men was common with around half of girls reporting this occurred within and outside of school. Just over one quarter $(27.1 \%)$ of girls reported they had had sex, among these, $18.8 \%$ had sex with a partner (e.g. willing), $46.6 \%$ were tricked or coerced to have sex, and $9.5 \%$ reported both being willing and being coerced.

\section{Characteristics associated with pregnancy}

Throughout the duration of the study, 53 (6.9\%) of the girls enrolled were or became pregnant, of whom 11 were pregnant at baseline. In unadjusted analyses, age and presence of mother or father were not associated with pregnancy risk among primary schoolgirls (Table 2). SES was significantly associated, with the highest rates in the SES lowest quintile, e.g. $12.5 \%$ among the lowest SES, and $3.5 \%$ among the highest SES quintile ( $X^{2}$ linear trend 11.8, $\mathrm{p}=0.008)$. Enrolment class was significantly associated with higher pregnancy rates among girls in the earlier $(5,6)$ compared with later $(7,8)$ classes $\left(X^{2}\right.$ linear trend 5.76, $\mathrm{p}=0.016)$. While being unhappy at home was not associated with pregnancy, being unhappy at school was significantly associated $(\mathrm{p}=0.043)$. Despite evidence of being harassed for sex by boys and men, it had no association with pregnancy.

Girls who had reported early menarche ( $<13$ years) had twice the rate of pregnancy compared with those starting menarche at 13 years or older, although this did not reach statistical significance $(p=0.062)$. Marriage by the end of the study was highly correlated with pregnancy, with $40.9 \%$ of pregnant girls becoming married, compared with $5.9 \%$ of non-pregnant girls $(\mathrm{p}<0.001)$.

\section{Characteristics associated with pregnancy: multivariate analyses}

Among 558 girls with full data on all risk characteristics of interest (including 36 pregnancies), SES remained strongly associated with girls in the lowest quintiles at a 2.5-fold higher risk of pregnancy compared with those in the highest quintiles [adjusted risk ratio (aRR) 2.66, 1.355.26; Table 3].

Girls who reported they were happy at school were less likely to become pregnant (aRR 0.50, 0.26-0.95) compared with those reporting they were not happy. Early menarche was also a significant risk factor with girls reaching menarche before age 13 years having a close to three-fold higher risk (aRR 2.96, 1.18-4.32) compared with girls beginning their menses at an older age. Class was not associated with pregnancy (class 5-6 vs 7-8: RR 1.12, 95\% CI $0.58-2.16, \mathrm{p}=0.73$ ) and neither was age (aRR 1.10, $95 \%$ 
CI 0.61-2.00). No interaction was noted between SES and being happy at school, or SES and early menarche. Inclusion of child marriage into the model found that the risk of pregnancy was highly associated with marriage with an 8-fold higher risk (aRR 8.18, 3.74-17.91, Table 4). Early menarche and SES remained associated with pregnancy in this model.

\section{Characteristics associated with child marriage}

Of the 766 girls enrolled, 22 (2.9\%) were married by the end of the study. Among the 558 girls for whom complete data on all variables were obtained, $11(2.0 \%)$ were married by the end of the study. Being pregnant was the strongest risk factor for marriage, with girls at a 13-fold (aRR 13.44, 5.50-32.83) higher risk of marrying by the end of the study if they became pregnant (Table 5). Reporting 'ever had sex' at baseline was an additional significant risk factor for child marriage (aRR 3.15, 1.55-6.38); when controlling for pregnancy, no other variables were significant. There was no interaction noted between 'ever had sex' and pregnancy for the risk on marriage. There were no marriages among girls with early menarche, and this factor could not be further evaluated.

\section{Pregnancy outcomes}

Birth outcomes were known for 36 of 53 pregnancies. Of the 36 , all were live births, with $33(91.7 \%)$ surviving up to follow-up and 3 deaths within one week of delivery. No participants reported or were identified to have spontaneous or induced abortion. Five $(14 \%)$ of the 36 girls resumed school, two of whom claimed they had never been pregnant, one transferred to another school and two resumed their current school. No sociobehavioural or economic characteristics were associated with infant survival, however all five resuming school had mothers present in their household. Notes on circumstances and outcomes related to the girls who became pregnant during the study confirmed they stopped attending school after pregnancy disclosure, in contrast to dropping out first and then becoming pregnant.

Table 1: Characteristics of Kenyan schoolgirls at baseline.

\begin{tabular}{|c|c|c|}
\hline Characteristics & Frequency & Percentage $(\%)$ \\
\hline \multicolumn{3}{|l|}{ Age at enrolment (years) } \\
\hline 14 & $412 / 766$ & 53.8 \\
\hline 15 & $268 / 766$ & 35.0 \\
\hline 16 & $86 / 766$ & 11.2 \\
\hline \multicolumn{3}{|l|}{ Parent present in household } \\
\hline Mother and father & $240 / 693$ & 34.6 \\
\hline Mother only & $237 / 693$ & 34.2 \\
\hline Father only & $62 / 693$ & 8.9 \\
\hline No parent & $154 / 693$ & 22.2 \\
\hline \multicolumn{3}{|l|}{ Class of participants at time of enrolment } \\
\hline 5 & $55 / 766$ & 7.2 \\
\hline 6 & $186 / 766$ & 24.3 \\
\hline 7 & $434 / 766$ & 56.7 \\
\hline 8 & $91 / 766$ & 11.9 \\
\hline \multicolumn{3}{|l|}{ SES of participants } \\
\hline 1 (lowest MCA) & $40 / 639$ & 6.3 \\
\hline 2 & $78 / 639$ & 12.2 \\
\hline 3 & $133 / 639$ & 20.8 \\
\hline 4 & $187 / 639$ & 29.3 \\
\hline 5 (highest MCA) & $201 / 639$ & 31.5 \\
\hline \multicolumn{3}{|l|}{ SES of participants (collapsed) } \\
\hline Lowest (quintile 1 and 2) & $118 / 639$ & 18.5 \\
\hline Highest (quintile 3-5) & $521 / 639$ & 81.5 \\
\hline Reported to be happy at home & $525 / 693$ & 75.8 \\
\hline Reported to be happy at school & $567 / 693$ & 81.8 \\
\hline \multicolumn{3}{|c|}{ Reported age at start of menstruation (years) } \\
\hline $10-12$ & $74 / 736$ & 10.1 \\
\hline $13-14$ & $591 / 736$ & 80.3 \\
\hline $15-16$ & $71 / 736$ & 10.4 \\
\hline Early menarche (below 13 years) & $74 / 736$ & 10.1 \\
\hline Reported heavy periods & $174 / 766$ & 22.7 \\
\hline Reported ever using pads & $638 / 766$ & 83.3 \\
\hline Boys/men harass for sex at school & $324 / 693$ & 46.8 \\
\hline Boys/men harass for sex out of school & $345 / 693$ & 49.8 \\
\hline
\end{tabular}


Characteristics

Ever had sex (exposure to sex, baseline)

Among ever exposure to sex (baseline)

Willing (sexual partner)

Tricked/coerced

Willing and tricked/coerced)

Menstrual product group

$\begin{array}{ll}\text { A } & 243 / 766 \\ \text { B } & 294 / 766 \\ \text { C } & 229 / 766\end{array}$

Note: MCA- multiple component analysis.
Frequency

191/693

Percentage $(\%)$

$36 / 191$

$89 / 191$

$66 / 191$

8.8

46.6

34.6

243/766

31.7

229/766

38.4

29.9

Table 2: Factors associated with pregnancy in Kenyan schoolgirls.

\begin{tabular}{|c|c|c|c|c|}
\hline Characteristics & Category & Pregnant (\%) & Chi square value & $P$ value \\
\hline \multirow{3}{*}{ Age at time of enrolment } & 14 & $30 / 412(7.3)$ & \multirow{3}{*}{0.22} & \multirow{3}{*}{0.90} \\
\hline & 15 & $17 / 268(6.3)$ & & \\
\hline & 16 & $6 / 86(7.0)$ & & \\
\hline \multirow{2}{*}{ Mother in household } & Mother present & $29 / 477(6.1)$ & \multirow{2}{*}{0.72} & \multirow{2}{*}{0.40} \\
\hline & Not present & $15 / 216(6.9)$ & & \\
\hline \multirow{2}{*}{ Father in household } & Father present & $22 / 302(7.3)$ & \multirow{2}{*}{0.79} & \multirow{2}{*}{0.37} \\
\hline & Not present & $22 / 391(5.6)$ & & \\
\hline \multirow{5}{*}{ SES } & 1 (lowest) & $5 / 40(12.5)$ & \multirow{5}{*}{ Linear trend 11.8} & \multirow{3}{*}{0.007} \\
\hline & 2 & $9 / 78(11.5)$ & & \\
\hline & 3 & $15 / 133(11.3)$ & & \\
\hline & 4 & $8 / 187(4.3)$ & & 0.008 \\
\hline & 5 (highest) & $7 / 201(3.5)$ & & \\
\hline \multirow{2}{*}{ SES (collapsed) } & Lowest (1-2) & $14 / 118(11.9)$ & \multirow{2}{*}{5.60} & \multirow{2}{*}{0.018} \\
\hline & Highest (3-5) & $30 / 521(5.8)$ & & \\
\hline \multirow{4}{*}{$\begin{array}{l}\text { Class of participants at time of } \\
\text { enrolment }\end{array}$} & 5 & $5 / 55(9.1)$ & \multirow{4}{*}{$\begin{array}{l}8.63 \\
\text { Linear trend } 5.76\end{array}$} & \multirow[t]{2}{*}{0.035} \\
\hline & 6 & $17 / 186(9.1)$ & & \\
\hline & 7 & $31 / 434(7.1)$ & & \\
\hline & 8 & 0/91 (0) & & 0.016 \\
\hline \multirow{2}{*}{ Class } & 5 or 6 & $22 / 241(9.1)$ & \multirow{2}{*}{2.67} & \multirow{2}{*}{0.10} \\
\hline & 7 or 8 & $31 / 525(5.9)$ & & \\
\hline \multirow{2}{*}{ Happy at home } & Yes & $31 / 525(5.9)$ & \multirow{2}{*}{0.72} & \multirow{2}{*}{0.40} \\
\hline & No & $13 / 168(7.7)$ & & \\
\hline \multirow{2}{*}{ Happy at school } & Yes & $31 / 567(5.5)$ & \multirow{2}{*}{4.08} & \multirow{2}{*}{0.043} \\
\hline & No & $13 / 126(10.3)$ & & \\
\hline Bovc/men haracs for cox at cchool & Yes & 19/324 (5.9) & 024 & 062 \\
\hline Boys/men harass for sex at school & No & $25 / 369(6.8)$ & 0.24 & 0.62 \\
\hline Boys/men harass for sex out of & Yes & $25 / 345(7.2)$ & 093 & 034 \\
\hline school & No & 19/348 (5.5) & 0.93 & 0.34 \\
\hline Farly menarche (below 13 vears) & Yes & $9 / 74(12.2)$ & 349 & 0062 \\
\hline 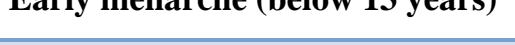 & No & $42 / 662(6.3)$ & 3.49 & 0.002 \\
\hline Heavy neriods & Yes & $11 / 174(6.3)$ & 013 & 072 \\
\hline Heavy periods & No & $42 / 592(7.1)$ & 0.13 & $0 . / 2$ \\
\hline Pad use (baseline) & Ever used pads & $46 / 638(7.2)$ & 050 & 048 \\
\hline Pad use (baseline) & Never used pads & $7 / 128(5.5)$ & 0.50 & 0.48 \\
\hline & A & $15 / 243(6.2)$ & & \\
\hline Intervention group & $\mathrm{B}$ & $18 / 294(6.1)$ & 1.67 & 0.43 \\
\hline & $\mathrm{C}$ & $20 / 229(8.7)$ & & \\
\hline Married (hy end of study) & Yes & $9 / 22(40.9)$ & 4063 & $<0001$ \\
\hline inartied (doy end or stuay) & Not reported & $44 / 744(5.9)$ & 40.03 & $<0.001$ \\
\hline
\end{tabular}


Table 3: Associations between pregnancy and baseline characteristics in schoolgirls $(\mathbf{n}=558)$.

\begin{tabular}{|c|c|c|c|c|c|c|}
\hline Characteristics & Category & $\begin{array}{l}\text { Pregnant by } \\
\text { endline }(\%)\end{array}$ & RR $(95 \%$ CI $)$ & $\begin{array}{l}\mathbf{P} \\
\text { value }\end{array}$ & $\operatorname{aRR}(95 \% \mathrm{CI})$ & $\begin{array}{l}P \\
\text { value }\end{array}$ \\
\hline \multirow{2}{*}{$\begin{array}{l}\text { Age group } \\
\text { (years) }\end{array}$} & Younger (14) & 21/311 (6.8) & $1.11(0.60,2.05)$ & \multirow{2}{*}{0.73} & $1.10(0.61,2.00)$ & \multirow{2}{*}{0.75} \\
\hline & Older (15-16) & $15 / 247(6.1)$ & 1 & & 1 & \\
\hline \multirow{2}{*}{ SES } & Lowest & $13 / 99(13.1)$ & $2.62(1.33,5.18)$ & \multirow{2}{*}{0.006} & $2.66(1.35,5.26)$ & \multirow{2}{*}{0.005} \\
\hline & Highest & 23/459 (5.0) & 1 & & 1 & \\
\hline \multirow{2}{*}{ Happy at school } & Yes & $25 / 454(5.5)$ & $0.52(0.27,1.01)$ & \multirow{2}{*}{0.052} & $0.50(0.26,0.95)$ & \multirow{2}{*}{0.036} \\
\hline & No & 11/104 (10.6) & 1 & & 1 & \\
\hline \multirow{2}{*}{$\begin{array}{l}\text { Early menarche } \\
\text { (below } 13 \text { years) }\end{array}$} & Yes & $7 / 50(14.0)$ & $2.45(1.28,4.69)$ & \multirow{2}{*}{0.007} & $2.96(1.18,4.32)$ & \multirow{2}{*}{0.014} \\
\hline & No & 29/508 (5.7) & 1 & & 1 & \\
\hline
\end{tabular}

Table 4: Associations between pregnancy and marriage and baseline risk characteristics in schoolgirls $(\mathrm{n}=558)$.

\begin{tabular}{|c|c|c|c|c|c|c|}
\hline Characteristics & Category & $\begin{array}{l}\text { Pregnant by } \\
\text { endline (\%) }\end{array}$ & $\mathbf{R R}(\mathbf{9 5 \%} \mathbf{C I})$ & $\begin{array}{l}\mathbf{P} \\
\text { value }\end{array}$ & $\operatorname{aRR}(95 \% \mathrm{CI})$ & $\begin{array}{l}P \\
\text { value }\end{array}$ \\
\hline \multirow{2}{*}{$\begin{array}{l}\text { Age group } \\
\text { (years) }\end{array}$} & Younger (14) & 21/311 (6.8) & $1.11(0.60,2.05)$ & \multirow{2}{*}{0.73} & $1.05(0.58,1.91)$ & \multirow{2}{*}{0.86} \\
\hline & Older (15-16) & $15 / 247(6.1)$ & 1 & & 1 & \\
\hline \multirow{2}{*}{ SES } & Lowest & 13/99 (13.1) & $2.62(1.33,5.18)$ & \multirow[t]{2}{*}{0.006} & $2.48(1.32,4.64)$ & \multirow[t]{2}{*}{0.005} \\
\hline & Highest & $23 / 459(5.0)$ & 1 & & 1 & \\
\hline \multirow{2}{*}{ Happy at school } & Yes & $25 / 454(5.5)$ & $0.52(0.27,1.01)$ & \multirow[t]{2}{*}{0.052} & $0.60(0.34,1.04)$ & \multirow[t]{2}{*}{0.067} \\
\hline & No & 11/104 (10.6) & 1 & & 1 & \\
\hline \multirow{2}{*}{$\begin{array}{l}\text { Early menarche } \\
\text { (below } 13 \text { years) }\end{array}$} & Yes & $7 / 50(14.0)$ & $2.45(1.28,4.69)$ & \multirow{2}{*}{0.007} & $2.61(1.38,4.92)$ & \multirow{2}{*}{0.003} \\
\hline & No & 29/508 (5.7) & 1 & & 1 & \\
\hline \multirow{2}{*}{$\begin{array}{l}\text { Married by } \\
\text { endline }\end{array}$} & Yes & $5 / 11(45.5)$ & $8.02(3.75,17.15)$ & \multirow{2}{*}{$<0.001$} & $8.18(3.74,17.91)$ & \multirow{2}{*}{$<0.001$} \\
\hline & No & $31 / 547(5.7)$ & 1 & & & \\
\hline
\end{tabular}

Table 5: Associations between marriage, pregnancy and baseline risk characteristics in schoolgirls $(\mathbf{n}=558)$.

\begin{tabular}{|c|c|c|c|c|c|c|}
\hline Characteristics & Category & $\begin{array}{l}\text { Married by } \\
\text { endline } \\
(\%)\end{array}$ & RR $(95 \%$ CI $)$ & $\begin{array}{l}P \\
\text { value }\end{array}$ & $\operatorname{aRR}(95 \% \mathrm{CI})$ & $\begin{array}{l}P \\
\text { value }\end{array}$ \\
\hline \multirow{2}{*}{$\begin{array}{l}\text { Age group } \\
\text { (years) }\end{array}$} & Younger (14) & 6/311 (1.9) & $0.95(0.31,2.91)$ & \multirow[t]{2}{*}{0.93} & $1.39(0.58,3.30)$ & \multirow[t]{2}{*}{0.46} \\
\hline & Older (15-16) & $5 / 247(2.0)$ & 1 & & & \\
\hline \multirow[b]{2}{*}{ SES } & Lowest & 2/99 (2.0) & $1.03(0.20,5.32)$ & \multirow{2}{*}{0.97} & & \\
\hline & Highest & $9 / 459(2.0)$ & 1 & & & \\
\hline \multirow{2}{*}{ Happy at school } & Yes & $7 / 454(1.5)$ & $0.40(0.19,0.85)$ & \multirow[t]{2}{*}{0.016} & $0.67,0.29-1.54$ & \multirow[t]{2}{*}{0.35} \\
\hline & No & $4 / 104(3.9)$ & 1 & & 1 & \\
\hline \multirow{2}{*}{$\begin{array}{l}\text { Early menarche } \\
\text { (below } 13 \text { years) }\end{array}$} & Yes & $0 / 50(0.0)$ & - & & - & \\
\hline & No & $11 / 508(2.2)$ & - & & - & \\
\hline \multirow{2}{*}{$\begin{array}{l}\text { Ever had sex (at } \\
\text { baseline) }\end{array}$} & Yes & $7 / 158(4.4)$ & $4.43(2.03,9.65)$ & \multirow{2}{*}{$<0.001$} & $3.15(1.55,6.38)$ & \multirow[t]{2}{*}{0.001} \\
\hline & No & $4 / 400(1.0)$ & 1 & & 1 & \\
\hline \multirow{2}{*}{$\begin{array}{l}\text { Pregnant by } \\
\text { endline }\end{array}$} & Yes & $5 / 36(13.9)$ & $12.08(3.96,36.85)$ & \multirow{2}{*}{$<0.001$} & $13.44(5.50$ & \multirow{2}{*}{$<0.001$} \\
\hline & Not reported & 6/522 (1.2) & 1 & & 32.83) & \\
\hline
\end{tabular}

\section{DISCUSSION}

In our cohort among Kenyan schoolgirls aged 14-16 years, $7 \%$ became or were pregnant. Risk factors included lower SES, early menarche, and being unhappy at school. Girls who were pregnant had a high chance of marrying, despite their young age, and most dropped out of school (91\%). A systematic review of 52 studies on prevalence and determinants of adolescent pregnancies among girls in the age group 10-19 years was conducted in 24 countries in
Africa, covering the project follow-up period. ${ }^{2}$ This detected a pooled prevalence of $18.8 \%$ of adolescent pregnancies, with a higher prevalence of $21.5 \%$ in East Africa. In the Demographic and Health Survey in Kenya of 2014, the percentage of girls 15-19y who had begun childbearing in Nyanza province was $22.2 \%$, which was down from $27.0 \%$ in the survey in 2008-2009. ${ }^{10,23}$ Among 16 years-old Kenyan girls, $8 \%$ had begun childbearing in 2014 , and $80 \%$ of these pregnancies were unintended. ${ }^{10,24}$ Data from a similar study in the same area reported nearly 
a quarter $(23.3 \%)$ of teenage girls (13-19 years) to have had a history of pregnancy in a study of 1952 girls. ${ }^{17}$ One review reported a percentage of first births of $7.7 \%$ among girls $<16$ years in Kenya. ${ }^{15}$

We noted a prevalence of $6.9 \%$ among schoolgirls aged 14-16 years; given the young age of this group, it is likely that the percentage will increase by the age of 19 years. Our estimate is likely to be an underestimate of total fertility, given that some pregnancies may have resulted in abortions and may not have been documented. Additionally, the lowest socio-economic strata may not have been well represented, because they may not have attended school, or may not have attended these schools where certain quality criteria for sanitation of schools were part of the inclusion criteria in this study. Age at the time of enrolment was not associated with pregnancy in either the bivariate or multivariate analyses, with a similar percentage of girls in each age group becoming pregnant over the period the study ran. This is inconsistent with a meta-analyses which identified increasing age as a risk factor for adolescent pregnancy. ${ }^{24}$ We note, however, that the age range we examined (14-16 years) was limited compared to other studies (15-19 years). ${ }^{22}$

Early menarche was associated with pregnancy; several African countries have reported a decreasing age of menarche in younger generations. ${ }^{25}$ It is possible that young girls may be unaware of pregnancy risk after menarche because comprehensive sexual and reproductive education is provided at a later age. ${ }^{26}$ Alternatively, girls who experience menarche may be viewed as sexually mature and face increased pressures and opportunities for sex and/or marriage. ${ }^{27}$ A systematic review of the effects of early menarche on sexual and reproductive health in LMIC noted that early menarche was associated with early sexual initiation, early pregnancy, and sexually transmitted infections, similar to observations in high-income countries. ${ }^{28}$ The review also identified an association between early menarche and child marriage.

In our study, girls in the lowest two SES categories were demonstrated to have an almost 2.5-fold higher risk of becoming pregnant compared with girls in the 3 highest SES categories. Similar patterns were reported before in Kenya, with $14.6 \%$ first births among girls less than 16 years in the lowest SES quintile and $3.6 \%$ in the highest quintile in 2014, and women aged 15-19 in the highest quintile having their first birth an average of 3.5 years later than women in the lowest quintile. ${ }^{10}$ The association between poverty and teenage pregnancy is globally well known. ${ }^{3}$ Girls from poor families may be vulnerable to exchanges of sexual favours for money; in addition, knowledge of and access to contraceptives may be reduced. ${ }^{29}$ A recent qualitative study discussed reports of drivers (taxi cars, motor cycles, or bicycles) in connection to teen pregnancies, citing a chief in western Kenya as saying poor schoolgirls in their mid-late teens may be persuaded to have sex with drivers who transport them to and from school in in exchange for pocket money. ${ }^{30}$
The association between unhappiness at school and increased pregnancy risk was of borderline significance. A previous study found girls with lower attendance rates were more likely to become pregnant than those with higher attendance. ${ }^{31}$ Another study from South Africa noted that instances of non-pregnancy-related grade repetition or temporary withdrawals from school were associated with a higher risk of pregnancy when in school. ${ }^{32}$ Unhappiness at school may also contribute to reduced re-entry in the school system after delivery (only 5 participants or $9 \%$ in our study), although practical concerns about childcare and income may also contribute to this. In 1994, the Ministry of Education in Kenya allowed girls to continue with education after dropping out of school due to pregnancy, however, girls still report being expelled from schools due to pregnancy. ${ }^{33,34}$

Prevention of adolescent pregnancies and improving the conditions for the mothers and their children from adolescent pregnancies are a complex issue, and a multifaceted approach is needed. ${ }^{1}$ Currently, this has not been adequately addressed. Kenya's parliament record of a senate debate documents speakers calling to attention the need for the government to fully enact its policy on adolescent sexual and reproductive health. ${ }^{35}$ It highlights that the current emphasis of the government is on integration back to school after childbirth, but few systems have been established to achieve this. The speaker encouraged the government to develop systems so that school age mothers have access to carers, either hired or family members, who can reliably look after their child while they are in school so that they can truly focus on their education.

A recent policy dialogue reported that there are more than 10 policies on youth and adolescent sexual reproductive health, but that these lack implementation due to insufficient funding. ${ }^{36}$ The report discusses why progress on preventing adolescent pregnancy has been slow and outlines the next steps that can be taken to implement significant change. Several recommendations were made; the final point calls for evidence-based interventions which would include identifying how to target and implement interventions. A systematic review identified 3 methods that were effective in studies at reducing pregnancy rates in Sub-Saharan Africa: Economic incentives, life-skills education and using facility-based provision of contraception. ${ }^{37}$ Using evidence-based interventions will be a key factor for reducing adolescent pregnancy in sub-Saharan Africa; however, up to now, progress has not been optimal. In a review of five subSaharan countries over the last 10 years, three were at the same level for percentage of women who had been pregnant by age 19 years (Kenya, Uganda, Zambia) and two showed an increase (Tanzania and Malawi). ${ }^{22}$

\section{Limitations}

This was a secondary analysis of data collected for a pilot intervention study on menstrual product interventions. 
Information on condom use, other forms of family planning, and care seeking, were not gathered. However, adolescent girls separately have informed in qualitative studies that they do not attend family planning, as they are stigmatised for not abstaining while unmarried; further, chemical contraceptives are considered dangerous with taboos asserting they will cause birth defects. ${ }^{34,38}$

We noted that data from this prior study may have some limitations due to any recent public health or economic changes, however, more recent studies in this impoverished area demonstrate no significant health, social, economic, or environmental changes in the study area. ${ }^{39}$ Some variables were incomplete, and this reduced the effective sample size, e.g. SES information was not available among all girls due to lack of linking with household data. While explained by logistical field activities and migration, we evaluated if missing data could have created biases. The prevalence of pregnancy, marriage and dropout were not different among participants with SES, compared against those without SES data for their household. Similarly, characteristics of risk, e.g. reported sex, being harassed for sex, and happiness at home and school were similar.

Age at time of established pregnancy was not recorded; the analyses instead used age at time of enrolment. However, given pregnancy outcomes occurred within 9 months, and all girls enrolled were between 14-16 years, misclassification related to age would have had minimal effect on the analyses. Age of menarche were less prone to this as girls made this estimate based on how many years they had been menstruating at the time of the study. We did not do pregnancy tests to identify pregnancy as it could have resulted in early disclosure of pregnancy and subsequent expulsion or dropout of the girls from school, thus, some pregnancies may have been missed among girls having a spontaneous or medically induced abortion.

Marriage dates were not recorded in the dataset, which limited the ability to determine if pregnancy occurred before or after marriage among girls identified as pregnant early in the cohort follow-up.

\section{CONCLUSION}

Adolescent pregnancy and child marriage are important public health issues; these girls are at risk of adverse reproductive health challenges and school dropout. Interventions which will help to protect teenage girls against unwanted pregnancy and enable them to reach their full potential in education and beyond are urgently needed.

\section{ACKNOWLEDGMENTS}

We extend our gratitude to schools, girls, staff, and stakeholders contributing to this study, and to the Director of KEMRI for approving the manuscript.
Funding: This work was supported by the UK-Medical Research Council/Department for International Development/Wellcome Trust Global Health Trials award (G1100677/1).

Conflict of interest: None declared

Ethical approval: The study was approved by the Institutional Ethics Committee (Kenya and UK)

\section{REFERENCES}

1. WHO. Adolescent pregnancy- WHO Fact Sheet, 2020. Available at: https://www.who.int/newsroomfactsheets/detail/adolesc ent-pregnancy. Accessed on 20 April 2021.

2. Kassa GM, Arowojolu AO, Odukogbe AA, Yalew AW. Prevalence and determinants of adolescent pregnancy in Africa: a systematic review and Meta-analysis. Reprod Health. 2018;15(1):195.

3. Yakubu I, Salisu WJ. Determinants of adolescent pregnancy in sub-Saharan Africa: a systematic review. Reprod Health. 2018;15(1):15.

4. Wodon Q, Male C, Montenegro C, Nguyen H, Onagoruwa A. The Cost of Not Educating Girls: Educating Girls and Ending Child Marriage: A Priority For Africa. Washington, DC: World Bank; 2018.

5. United Nations Fund for Population Activities. Girlhood, not motherhood: Preventing adolescent pregnancy. New York, USA: United Nations Populations Fund; 2015.

6. Karra M, Lee M. Human capital consequences of teenage childbearing in South Africa. Washington, DC: Population Reference Bureau; 2012.

7. Madeni F, Horiuchi S, Iida M. Evaluation of a reproductive health awareness program for adolescence in urban Tanzania--a quasi-experimental pre-test posttest research. Reprod Health. 2011;8:21.

8. Ahikire J, Aramanzan M. A survey on re-entry of pregnant girls in primary and secondary schools in Uganda. Uganda: UNICEF; 2011: 1-45.

9. Morara AN, Chemwei B. Drop out among Pupils in Rural Primary Schools in Kenya: The Case of Nandi North District, Kenya. J Edu Pract. 2013;4(19):1-12.

10. Kenya National Bureau of Statistics, Ministry of Health Kenya, National AIDS Control Council, Kenya Medical Research Institute, National Council for Population and Development, ICF International. Kenya Demographic and Health Survey 2014. USA: DHS; 2015.

11. Wodon Q, Male C, Montenegro C, Nguyen H, Onagoruwa A. The cost of not educating girls: Educating girls and ending child marriage: A priority for Africa. Washington, DC: World Bank; 2018.

12. Ganchimeg T, Ota E, Morisaki N, Laopaiboon M, Lumbiganon $\mathrm{P}$, Zhang J, et al. Pregnancy and childbirth outcomes among adolescent mothers: a World Health Organization multicountry study. BJOG. 2014;121(1):40-8.

13. WHO. Global health estimates: deaths by cause, age, sex, by country and by region, 2000-2016, 2020Available at: https://www.who.int/healthinfo/global_burden_disease/ en/. Accessed on 20 April 2021.

14. United Nations. The Sustainable Development Goals Report 2016. New York, USA: United Nations; 2016. 
15. Neal SE, Mouli V, Chou D. Adolescent first births in East Africa: disaggregating characteristics, trends and determinants. Reprod Health. 2015;12:13.

16. Ministry of Health National Council for Population and Development Kenya, Ministry of Planning and National Development Kenya, USAID, Division of Reproductive Health. Kenya Adolescent Reproductive Health And Development Policy Implementation Assessment Report. Washington, DC: Population Reference Bureau; 2013.

17. Omoro T, Gray SC, Otieno G. Teen pregnancy in rural western Kenya: a public health issue. Int $\mathrm{J}$ Adolesc Youth. 2018;23(4):399-408.

18. Howard PA, Nyothach E, Kuile FO, Omoto J, Wang D, Zeh C, et al. Menstrual cups and sanitary pads to reduce school attrition, and sexually transmitted and reproductive tract infections: a cluster randomised controlled feasibility study in rural Western Kenya. BMJ Open. 2016;6(11):13229.

19. Odhiambo FO, Laserson KF, Sewe M, Hamel MJ, Feikin DR, Adazu K, et al. Profile: the KEMRI/CDC Health and Demographic Surveillance System--Western Kenya. Int J Epidemiol. 2012;41(4):977-87.

20. Alexander K, Oduor C, Nyothach E. Water, Sanitation and Hygiene Conditions in Kenyan Rural Schools: Are Schools Meeting the Needs of Menstruating Girls? Water. MDPI. 2014;6:1453-66.

21. Cummings P. Methods for estimating adjusted risk ratios. Stata J. 2009;9:175-96.

22. Wado YD, Sully EA, Mumah JN. Pregnancy and early motherhood among adolescents in five East African countries: a multi-level analysis of risk and protective factors. BMC Pregnancy Childbirth. 2019;19(1):59.

23. Kenya National Bureau of Statistics, ICF Macro. Kenya Demographic and Health Survey 2008-09. USA: Kenya National Bureau of Statistics (KNBS) and ICF Macro; 2010.

24. Wado YD, Sully EA, Mumah JN. Pregnancy and early motherhood among adolescents in five East African countries: a multi-level analysis of risk and protective factors. BMC Pregnancy Childbirth. 2019;19(1):59.

25. Garenne M. Trends in age at menarche and adult height in selected African countries (1950-1980). Ann Hum Biol. 2020;47(1):25-31.

26. Sidze EM, Stillman M, Keogh S. From paper to practice: Sexuality education policies and their implementation in Kenya. Kenya: Gutmacher Institute; 2017.

27. Sarfo EA, Yendork JS, Naidoo AV. Examining the intersection between marriage, perceived maturity and child marriage: perspectives of community elders in the Northern region of Ghana. Cult Health Sex. 2021;23(7):991-1005.

28. Ibitoye M, Choi C, Tai H, Lee G, Sommer M. Early menarche: A systematic review of its effect on sexual and reproductive health in low- and middle-income countries. PLoS One. 201;12(6):78884.
29. Nash K, Malley G, Geoffroy E, Schell E, Bvumbwe A, Denno DM. "Our girls need to see a path to the future" -perspectives on sexual and reproductive health information among adolescent girls, guardians, and initiation counselors in Mulanje district, Malawi. Reprod Health. 2019;16(1):8.

30. Mkutu K, Mkutu TR. Public health problems associated with "boda boda" motorcycle taxis in Kenya: The sting of inequality. Aggression and Violent Behavior. 2019;47:245-52.

31. Stoner MCD, Rucinski KB, Edwards JK, Selin A, Hughes JP, Wang J, et al. The Relationship Between School Dropout and Pregnancy Among Adolescent Girls and Young Women in South Africa: A HPTN 068 Analysis. Health Educ Behav. 2019;46(4):559-68.

32. Grant MJ, Hallman KK. Pregnancy-related school dropout and prior school performance in KwaZuluNatal, South Africa. Stud Fam Plann. 2008;39(4):36982.

33. Kenya Department of Development Coordination. National Poverty Eradication Plan 1999-2015. Kenya: Government Printers; 1999.

34. Oruko K, Nyothach E, Gutierrez E, Mason L, Alexander $\mathrm{K}$, Vulule $\mathrm{J}$, et al. 'He is the one who is providing you with everything so whatever he says is what you do': A Qualitative Study on Factors Affecting Secondary Schoolgirls' Dropout in Rural Western Kenya. PLoS One. 2015;10(12):144321.

35. Parliament of Kenya. Hansard Report of Senate Debates; Wednesday, November 14, 2018, 2018. Available at: arliament.go.ke/sites/default/files/2018-

11/Wednesday $\% 2 \mathrm{C} \% 2014$ th $\% 20$ November $\% 2 \mathrm{C} \% 2020$ 18. Accessed on 20 April 2021.

36. African Institute for Development Policy, United Nations Fund for Population Activities. Policy Dialogue: Tackling Teen Pregnancy in Kenya. Kenya: AFIDEP; 2019.

37. Hindin MJ, Kalamar AM, Thompson TA, Upadhyay UD. Interventions to Prevent Unintended and Repeat Pregnancy Among Young People in Low- and MiddleIncome Countries: A Systematic Review of the Published and Gray Literature. J Adolesc Health. 2016;59(3):8-15.

38. Dellicour S, Desai M, Mason L, Odidi B, Aol G, Howard PA, Laserson KF, et al. Exploring risk perception and attitudes to miscarriage and congenital anomaly in rural Western Kenya. PLoS One. 2013;8(11):80551.

39. Zulaika G, Kwaro D, Nyothach E, Wang D, Gutierrez E, Mason L, et al. Menstrual cups and cash transfer to reduce sexual and reproductive harm and school dropout in adolescent schoolgirls: study protocol of a clusterrandomised controlled trial in western Kenya. BMC Public Health. 2019;19(1):1317.

Cite this article as: Nyothach E, Ambrose E, Eijk AMV, Obor D, Mason L, Oduor C, et al. Pregnancy and marriage among teenage schoolgirls in rural western Kenya; a secondary analysis of a menstrual solution feasibility cohort study. Int J Reprod Contracept Obstet Gynecol 2021;10:3277-86. 